\title{
Derecho disciplinario militar y derechos humanos en Colombia 2004-2014 ${ }^{1}$
}

\section{Military Disciplinary Law and Human Rights in Colombia 2004-2014}

Diana Yulieth Montero Perdomo ${ }^{2}$

Recepción: 9 de septiembre de 2016 Aprobación: 20 de enero de 2017

\section{RESUMEN}

En Colombia el derecho disciplinario militar (DDM) cumple una función importante en la promoción y protección de los Derechos Humanos, por lo cual es pertinente verificar los antecedentes históricos, la situación actual del DDM y cómo este coadyuva a la mejora continua de los DD. HH. en las fuerzas militares, en especial, en el fortalecimiento de tales derechos al interior del Ejército Nacional.

Palabras clave: derecho disciplinario militar (DDM), justicia penal militar (JPM), transversalización, poder preferente.

1 Artículo producto del proyecto de investigación El derecho disciplinario militar y los Derechos Humanos para optar al título de Magister en Derechos Humanos y Derecho Internacional de los Conflictos Armados de la Escuela Superior de Guerra.

2 Magister en Derechos Humanos y Derecho Internacional de los Conflictos Armados, Escuela Superior de Guerra; Especialista en Derecho Penal y Criminología, Universidad Libre de Colombia, y en Derechos Humanos, Universidad Externado de Colombia; Abogada, Universidad Cooperativa de Colombia. Correo Electrónico: diana.montero@armada.mil.co, diakamon@yahoo.es 


\section{Abstract}

The military disciplinary law (here on DDM) in Colombia, plays an important role in the in promotion and prevention of Human Rights, reason why it is relevant to check the historical background, the current situation DDM and this contributes to the continuous improvement of the Human Rights of the armed forces, especially in the strengthening of these within the national army.

Keywords: Discipline Law Disciplinary Military (DLDM), Penal Military Justice (PMJ), mainstreaming, preferential power.

\section{INTRODUCCIÓN}

Con ocasión de los cuestionamientos realizados a las fuerzas militares por violaciones a los Derechos Humanos, se hace necesario analizar la función que cumple el DDM en la promoción y protección de dichos derechos al interior de tales fuerzas. Con tal propósito, se identificarán los factores del DDM en los casos de la justicia penal militar, la responsabilidad extracontractual y la responsabilidad internacional del Estado, así como su impacto a nivel nacional e internacional, particularmente en el periodo 2004-2014, en consonancia con la Ley 836 de 2003 que establece el régimen disciplinario para las FF. MM. de Colombia.

\section{Diseño METOdológico}

El presente trabajo se desarrolla con el método histórico-inductivo: inicia con el planteamiento del problema respecto de qué función cumple el DDM en la promoción y protección de los Derechos Humanos por parte de las fuerzas militares en Colombia y termina con una síntesis explicativa de dicho problema.

Así mismo, presenta estudios estadísticos en DDM y Derechos Humanos en Colombia a fin de demostrar cómo tal derecho es importante para la promoción y protección de los DD. HH. y cómo impacta de manera positiva a nivel nacional e internacional, más aun en el contexto de los diálogos de paz que generarán una transformación de las FF. MM. 
Igualmente, realiza una revisión exhaustiva de la referencias en DDM, como son los informes de la Oficina en Colombia del Alto Comisionado de las Naciones Unidas para los Derechos (OCACNUDU), desde 2004 hasta 2014, y las sentencias de la Corte Interamericana de Derechos Humanos (CIDH).

De conformidad con lo anterior, se analiza la historia del DDM en Colombia y el fortalecimiento de la justicia penal militar y el derecho disciplinario; se esboza la situación actual del DDM y la de los Derechos Humanos en Colombia y se finaliza con las diferentes soluciones, criticas al régimen disciplinario y cómo este podría coadyuvar a la promoción y protección de los Derechos Humanos en las fuerzas militares de Colombia.

\section{El DeRecho disciplinario militar y los Derechos Humanos}

Para responder a la pregunta acerca de qué función cumple el DDM en la promoción y protección de los Derechos Humanos por parte de las fuerzas militares en Colombia, es necesario analizar la historia de dicho derecho en nuestro país y su situación actual, así como la de los DD. HH.

\section{Historia DEL DERECHO DISCIPLINARIO MILITAR}

El DDM surgió por la necesidad de mantener unas fuerzas militares organizadas y disciplinadas, es decir, como fundamento para la existencia de dichas fuerzas (Rojas, 1990). Tal derecho evoluciona a medida que los conflictos cambian, así que en el siguiente aparte se analiza el DDM en Colombia, según las dos últimas constituciones, la de 1886 y la de 1991.

Con la Constitución de 1886, de tendencia liberal derechista (Valencia, 2012), se realizaron trece reformas al DDM iniciando con: 1) el Decreto 865 de 1911, $R e$ glamento de castigos disciplinarios y de reclamos; 2) el Decreto 1277 de 1923 que reglamentó los Tribunales de Honor; 3) el Decreto 953 de 1940 que reglamentó los tribunales de honor; 4) el Decreto 2295 de 1940, Reglamento de castigos disciplinarios y de reclamos para el Ejército; 5) el Decreto 837 de 1942, mediante el cual se aprobó 
el Reglamento de castigos disciplinarios de la Armada Nacional; 6) el Decreto 2302 de 1943 por el cual se reemplazaron los regímenes que habían implementado los tribunales de honor; 7) el Decreto 2175 de 1951, Reglamento de régimen disciplinario para el personal de las fuerzas militares; 8) el Decreto 313 de 1956, por el que se complementó lo de los tribunales de honor; 9) el Decreto 920 de 1963 por el que se determina la competencia para conocer en segunda instancia de los fallos de los tribunales de honor; 10) el Decreto 2782 de 1965, Reglamento de régimen disciplinario para las fuerzas militares; 11) el Decreto 1615 de 1966, que modificó el capítulo VII, sexta parte del Decreto 2782 de 1965; 12) el Decreto 1776 de 1979 que implementó como nuevo Reglamento de régimen disciplinario para las fuerzas militares, (Fuerzas Militares, 1980) y 13) el Decreto 085 de 1989 que implementó el nuevo Reglamento de régimen disciplinario para las fuerzas militares (Mejía, 2003).

Posteriormente, con la Constitución de 1991, de tendencia social de derecho y democrática (Valencia, 2012), el DDM fue incluido en el artículo 217 de la Carta, como régimen disciplinario militar ${ }^{3}$ (Const., 1991).

Como se enunció anteriormente, el Decreto 085 de 1989 tuvo vigencia hasta el Decreto 1797 de 2000 (Mejía, 2003), el cual implementó el nuevo Reglamento de régimen disciplinario para las fuerzas militares, aplicándose solo la parte sustantiva, porque la procedimental seguía la Ley 200 de 1995, con lo cual se daba una suerte de hibridación, por lo que surgió la necesidad de tener un DDM autónomo, independiente tanto en lo procedimental como en lo sustancial, dando origen a la Ley 836 de 2003.

\section{Situación del derecho disciplinario militar en Colombia}

En la actualidad, el DDM tiene un rango constitucional creado mediante la Ley 836 de 2003, a la cual le fue realizado el control de constitucionalidad mediante Senten-

3 Se transcribe de manera literal el artículo 217 de la Constitución Política de Colombia: "La nación tendrá para su defensa unas fuerzas militares permanentes constituidas por el Ejército, la Armada y la Fuerza Aérea. Las fuerzas militares tendrán como finalidad primordial la defensa de la soberanía, la independencia, la integridad del territorio nacional y del orden constitucional. La ley determinará el sistema de reemplazos en las fuerzas militares, así como los ascensos, derechos y obligaciones de sus miembros y el régimen especial de carrera, prestacional y disciplinario, que les es propio" (Const., 1991). 
cia C-431 de 2004, indicando que las faltas disciplinarias corresponden a una forma de ejercicio de la potestad sancionadora del Estado y que este debe estar sustentado en el principio de dignidad humana que regula los Derechos Humanos (Sentencia, C-578 de 2002).

Es de resaltar que los principios del DDM se encuentran regulados en el Título I, capitulo único de la Ley 836 de 2003, en especial en el artículo 13 que trata de la prevalencia de los principios rectores (Mejía, 2003) y que se encuentra en concordancia con normas internacionales de Derechos Humanos avocando el bloque de constitucionalidad del artículo 93 de la Carta Política Internacional (Mejía, 2006). En este sentido, enuncia el exprocurador general de la nación Edgardo Maya Villazón que el DDM se encuentra tipificando conductas como faltas disciplinarias gravísimas que vulneran los DD. HH. y el Derecho Internacional Humanitario (DIH) al incluir normativa de carácter internacional (Instituto Colombiano de Derecho Disciplinario, 2012).

Por otro lado, la Procuraduría General de la Nación tiene la figura de poder preferente regulada por el artículo 277 de la Constitución Política, tema sobre el cual la Corte Constitucional se ha pronunciado en el sentido de que es una facultad de vigilancia que posee el ente de control (Sentencia C-500 de 2014). ${ }^{4}$

Al respecto, dicho ente, mediante Resolución 346 del 3 de octubre de 2002, manifiesta que en principio asumirá la investigación disciplinaria por hechos de transcendencia, entre los cuales se atente contra los DD. HH. y el DIH (Procuraduría General de la Nación, 2002), lo que quiere decir que los casos relevantes en materia de Derechos Humanos se encuentran ante este ente de control y no ante el DDM.

4 Sentencia C-500 de 2014: "El carácter superior de la vigilancia que prevé el artículo 277 implica, entre otras cosas, que el Procurador se encuentra habilitado para adelantar la vigilancia de todos los funcionarios, incluyendo a aquellos a cuyo cargo se encuentra la vigilancia en las diferentes entidades del Estado. En ese sentido, se trata de una competencia extendida, puesto que tiene también por objeto controlar a quienes controlan y, por ello, el artículo la refiere como superior. A su vez, el carácter preferente supone la competencia para desplazar a las autoridades a cuyo cargo se encuentra originariamente el control disciplinario interno a fin de desarrollarlo directamente. En esa medida, salvo que se trate de competencias exclusivas del Procurador o de sus agentes o delegados, el control disciplinario está radicado originalmente en la oficina correspondiente de la respectiva entidad, que podrá ser separada del conocimiento del asunto por decisión de la Procuraduría en las condiciones previstas por la ley". 


\section{Situación de los Derechos Humanos en Colombia}

En la actualidad, el Estado colombiano ha firmado todos los convenios y tratados en materia de Derechos Humanos (ACNUDH, 2003), a lo que se agrega que la Constitución Política está fundamentada en un Estado social y democrático de derecho, el cual tiene como pilar el respeto de la dignidad humana (Const., 1991). En este mismo sentido, los Derechos Humanos son reconocidos en todo tiempo y lugar y no pueden suspenderse ni siquiera en los estados de excepción (Const., 1991, art. 215).

Así mismo, el 29 de noviembre de 1996, Colombia suscribió el acuerdo5 para crear una oficina de Derechos Humanos por la ACNUDH ${ }^{6}$ (Consejo de Derechos Humanos Naciones Unidas, 1998), debido al escalamiento del Conflicto armado (Echandía, 2006), escalamiento durante el cual se cometieron múltiples violaciones a los Derechos Humanos (civiles y políticos, entre los cuales se encuentra el derecho a la vida), por parte de la fuerza pública y grupos armados ilegales, como violaciones, amenazas, desapariciones forzosas, tratos crueles y degradantes y represión de las libertades sindicales, de expresión y de pensamiento, así como del ejercicio del derecho al debido proceso, entre otros (Consejo de Derechos Humanos, Naciones Unidas, 1998).

Por esta razón, anualmente, desde 1997, la Oficina en Colombia del Alto Comisionado de las Naciones Unidas para los Derechos Humanos (OCACNUDH) viene realizando los informes que permiten el análisis del comportamiento de las fuerzas militares respecto de los Derechos Humanos durante el periodo 2004-2014, con la finalidad de verificar la aplicación de la Ley 836 de 2013.

En el informe correspondiente a 2004, la OCACNUDH manifiesta que la situación de los Derechos Humanos en Colombia es cada vez más crítica y compleja por la evolución del conflicto armado interno y por los diferentes actores estatales y no estales involucrados (FARC, AUC y ELN). Señala que hubo muchas violaciones de los DD. HH. e impunidad, pese a las alertas de riesgo emitidas por el procurador general de la nación y el retiro de miembros de la fuerza pública por casos de corrupción,

5 Firmado por la ministra de Relaciones Exteriores de Colombia, señora María Emma Mejía Vélez y el entonces Alto Comisionado de Naciones Unidas para los Derechos Humanos, seńor José Ayala Lasso.

6 Según quien la ocupe, el o la Alta Comisionada de Naciones Unidas para los Derechos Humanos. 
faltas en el servicio y lesiones ( $\left.\mathrm{CDHNU}^{7}, 2005\right)$. Indica igualmente la conducta reiterativa de detenciones individuales y masivas, en especial, por el Ejército Nacional, el cual ha recibido llamados de atención por parte del procurador y el defensor del pueblo (CDHNU, 2005). Finalmente, realiza 27 recomendaciones en materia de prevención y protección, Estado de derecho, impunidad, políticas económicas y sociales, promoción de una cultura de respeto a los Derechos Humanos y asesoramiento y cooperación técnica de la oficina en Colombia del ACNUDH.

En el informe correspondiente a 2005, la OCACNUDH informa que la situación de los Derechos Humanos se continúa caracterizando por las violaciones graves a los derechos civiles y políticos; manifiesta la existencia de un patrón de muerte en personal civil y desapariciones forzadas y tratos crueles y degradantes, y reafirma las recomendaciones realizadas en el informe anterior (CDHNU, 2006).

En el informe correspondiente a 2006, la OCACNUDH menciona por primera vez el contexto general del país, la evolución del conflicto y la perspectiva de paz; observa que el Gobierno ha adoptado políticas de promoción y prevención en materia de DD. HH., incluidas en los planes de desarrollo de 516 municipios y de 31 departamentos; señala la adopción de una política de lucha contra la impunidad, la adhesión del Ministerio de Defensa a las recomendaciones para fortalecer la capacitación en materia de DD. HH., la introducción de la figura del Asesor Jurídico y el nombramiento de oficiales del alto rango como inspectores en cada división (CDHNU, 2007).

En el informe correspondiente a 2007, la OCACNUDH considera que los hechos políticos de mayor impacto fueron los proceso judiciales contra los líderes desmovilizados de grupos paramilitares (Ley 975 de 2005), las investigaciones judiciales contra servidores públicos de alto nivel por vínculos con estos grupos, la aparición de nuevos grupos, la realización de elecciones y la persistencia en la lucha contra la impunidad. En este periodo se reabre la investigación de los hechos del Palacio de Justicia y se emiten condenas por las mal llamadas ejecuciones extrajudiciales (caso Saravena, Arauca). Por otro lado, la Corte Interamericana de Derechos Humanos (CIDH) condena al Estado por la ejecución extrajudicial de un líder de la comunidad Nasa (Cauca, febrero de 1988). Así mismo, el Estado colombiano aceptó la responsabilidad en el caso de

7 Consejo de Derechos Humanos Naciones Unidas. 
la Rochela, Santander, enero de 1989 (CDHNU, 2008). No obstante, el panorama continúa con las ejecuciones extrajudiciales atribuidas a miembros de la fuerza pública, en especial, del Ejército Nacional, por lo cual el Ministerio de Defensa Nacional crea en este periodo la Política Integral de Derechos Humanos y Derecho Internacional Humanitario (Ministerio de Defensa Nacional, 2008) que cuenta con cinco líneas de acción, entre ellas, la Disciplina, la cual se desarrolla en 2008 (CDHNU, 2008). Es de resaltar que el 9 de septiembre de 2007, se extiende el mandato de la ACNUDH hasta el 30 de octubre de 2010 (CDHNU, 2009).

En el informe correspondiente a 2008, la OCACNUDH señala que se continúa estigmatizando a los defensores y defensoras de Derechos Humanos y que pese a la políticas del Ministerio de Defensa de protección de Derechos Humanos y de "tolerancia cero" (p. 2), siguen las quejas y víctimas registradas por conductas de miembros de la fuerza pública; la Fiscalía General de la Nación reporta 716 presuntas violaciones a los $\mathrm{DD}$. $\mathrm{HH}$. e infracciones al DIH y considera que ocurrieron por la ausencia de un control eficaz por los comandantes militares, aunado a los incentivos económicos, reconocimientos otorgados e impunidad al interior de la JPM respecto del Ejército Nacional, todo lo cual generó la repetición de las conductas violatorias (CDHNU, 2009).

En el informe correspondiente a 2009, la OCACNUDH señala la coerción a la rama judicial violando el principio de independencia, las actividades ilegales dirigidas por el Departamento Administrativo de Seguridad (DAS) y la continuación de los homicidios y amenazas contra los defensores y defensoras de Derechos Humanos, sindicalistas, periodistas y comunidad LGTBI. Anota que disminuyeron las quejas contra los miembros de la fuerza pública en siete casos, en especial en el Ejército Nacional, que la JPM continúa remitiendo a la justicia ordinaria los casos de violaciones de Derechos Humanos y que tienen 249 casos de colisión de competencia (CDHNU, 2010).

En el informe correspondiente a 2010, la OCACNUDH anota que hay elección de Congreso y que con el presidente Juan Manuel Santos Calderón, el conflicto armado interno afecta notablemente los Derechos Humanos. Indica que durante este periodo se redujeron las denominadas ejecuciones extrajudiciales; que la Fiscalía General de la Nación tenía 1488 casos con 2547 víctimas, que se dictaron 125 sentencias, que de estas 22 fueron absolutorias y, por último, que los casos de muerte de personas 
son consecuencia del uso excesivo de la fuerza pública, en especial, por la Policía Nacional, así como la violencia sexual realizada por miembros de las fuerzas militares y grupos armados ilegales ${ }^{8}$ (CDHNU, 2011). La OCACNUDH recomienda que las políticas implementadas por el Ministerio de Defensa sean progresivas con el fin de prevenir retrocesos (CDHNU, 2011), y el MDN crea la Directiva Permanente N. ${ }^{\circ}$ 11 de 2010, Cero tolerancia contra la violencia sexual (Ministerio de Defensa Nacional, 2014, p. 67).

En el informe correspondiente a 2011, la OCACNUDH valora el esfuerzo realizado por el Gobierno nacional, al implementar políticas públicas de promoción y protección de Derechos Humanos y aprobar la Ley 1448 de 2011, Ley de víctimas y restitución de tierras. No obstante, señala que continúan las amenazas contra los defensores y defensoras de Derechos Humanos, que fueron asesinados veinte sindicalistas, que las muertes extrajudiciales que son graves violaciones resurgieron en Arauca, Bogotá, Cauca y Cesar, que la Unidad de Derechos Humanos de la Fiscalía informa que tenía 1622 casos de presuntos homicidios de la fuerza pública, de los cuales se habían proferido 148 sentencias condenatorias (CDHNU, 2012).

En el informe correspondiente a 2012, la OCACNUDH ve como motivo de esperanza el hecho de que el 26 de agosto de 2012, el Gobierno y las FARC-EP firman un acuerdo para la terminación del conflicto armado; ${ }^{2}$ considera que las FF. MM. tienen una confusión en la aplicación entre los diferentes marcos jurídicos; señala que durante este periodo no recibió ningún informe de homicidios realizados por miembros de las FF. MM., y continúa recibiendo denuncias por el uso indebido o excesivo de la fuerza y por violencia sexual por parte del Ejército Nacional (CDHNU, 2013).

En el informe correspondiente a 2013, la OCACNUDH aplaude las diferentes actividades desarrolladas por el Estado colombiano en la mejora continua para la pro-

8 De los cinco casos mencionados en el Informe anual de la ACNUDH sobre la situación de los Derechos Humanos en Colombia en 2011, página 25 del mismo, dos son del Ejército Nacional, uno de la Armada Nacional, uno de las FARC y uno de bandas criminales (CDHNU, 2011).

9 Los temas prioritarios son: 1) Desarrollo agrario, 2) Participación política, 3) Terminación del conflicto armado, 4) Drogas ilícitas, 5) Derecho de las víctimas y 6) Mecanismos de aplicación, verificación y solución de controversias relacionadas con el acuerdo, a la fecha solo se han acordado tres temas (Desarrollo agrario, Participación política y Drogas ilícitas). (Policía Nacional, 2015). 
tección de los DD.HH, como son la reparación de las víctimas y la tarea ardua que realiza la Unidad de Restitución de Tierras (URT); por otro lado a diciembre de 2013 existían 5.966.211 víctimas del conflicto armado; ya no se informa de las mal llamadas ejecuciones extrajudiciales, sino que se está a la expectativa de los diálogos de La Habana y cómo sería el proceso transicional del conflicto a la paz, pero el ACNUDH manifiesta que es preocupante que no se esté dando la información de las presuntas violaciones actuales y pasadas de la fuerza pública a los Derechos Humanos, lo que genera una negación del reconocimiento. Así mismo, observa en este periodo una privación arbitraria de la vida, consecuencia de la falta de planificación, disciplina militar y mando y control, así como el inicio de procesos penales y disciplinarios en los que no se evidencia celeridad, lo cual genera inseguridad jurídica e impunidad. Finalmente, preocupa a la OCACNUDH que frente al proceso de paz, las FF. MM. no reconozcan sus violaciones a los Derechos Humanos ni sus infracciones al DIH (CDHNU, 2014).

En el informe correspondiente a 2014, la OCACNUDH manifiesta que el Ejército Nacional continúa violando el derecho humano a la vida con la excusa de que se trata de errores militares; señala que persisten las mal llamadas ejecuciones extrajudiciales y registra incidentes entre las FF. MM. y los indígenas, por lo que les recuerda a dichas fuerzas la importancia de la Directiva Permanente N. ${ }^{\circ} 016$ de 2006 (Ministerio de Defensa Nacional, 2014) para la promoción y protección de los DD. HH. de este grupo de especial protección (CDHNU, 2015).

En la actualidad, el Estado colombiano ha sido sancionado quince (15) veces por la Corte Interamericana de Derechos Humanos por las siguientes violaciones a los Derechos Humanos (Corte Interamericana de Derechos Humanos, 2015): 1) Caballero Delgado y Santana, sentencia del 8 de diciembre de 1995; 2) Las Palmeras, sentencia del 6 de diciembre de 2001;3) 19 Comerciantes, sentencia del 5 de julio de 2014; 4) Wilson Gutiérrez Soler, sentencia del 12 de septiembre de 2005; 5) Mapiripán, sentencia del 15 de septiembre de 2005; 6) Pueblo Bello, sentencia del 31 de enero de 2006; 7) Masacre de Ituango, sentencia del $1 .^{\circ}$ de julio de 2006; 8) Masacre de la Rochela, sentencia del 11 de mayo de 2007; 9) Germán Escué Zapata, sentencia del 4 de julio de 2007; 10) Jesús María Valle, sentencia del 27 de noviembre de 2008; 11) Manuel Cepeda, sentencia del 26 de mayo de 2010; 12) Vélez Restrepo y familia, sentencia del 3 de septiembre de 2012; 13) Masacre de Santo Domingo, senten- 
cia del 30 de noviembre de 2012;14) Comunidades afrodescendientes desplazadas de la cuenca del río Cacarica (Operación Génesis), sentencia del 20 de noviembre de 2013, y 15) Rodríguez Vera y otros (Desaparecidos del Palacio de Justicia), sentencia del 14 de noviembre de 2014.

En estas sentencias, la CIDH ha sido reiterativa en señalar la inoperatividad de la justicia en la búsqueda de la verdad de los hechos, la reparación y la justicia de los mismos y su no repetición, y en que el Estado debe responder por el deber de garantía, protección y respeto a los DD. HH. (Corte Interamericana de Derechos Humanos, 2015).

Por último, se analizan las diferentes medidas cautelares y provisionales del Sistema Interamericano de Derechos Humanos, en las cuales las fuerzas militares tienen el deber de cumplimiento. Para ello se recibió la información de las respectivas fuerzas (Ejército, Armada y Fuerza Aérea) del periodo 2004-2014, así:

El Ejército Nacional ha recibido 64 medidas cautelaras, 3 medidas provisionales y 139 peticiones (Ejército Nacional, 2015).

La Armada Nacional ha recibido 12 medidas cautelares, 1 provisional, la de Curvaradó (la de Jiguamiandó fue levantada en 2013), 15 peticiones y 1 demanda por la Operación Génesis de la cual se profirió sentencia el 20 de noviembre de 2013 (Armada Nacional, 2015).

La Fuerza Aérea informa que no tiene medidas cautelares, provisionales o peticiones ante el Sistema Interamericano de Derechos (FAC, 2015).

\section{Posibles Soluciones Para la promoción y PRotección de los Derechos Humanos en Colombia}

En las siguientes líneas se analiza cómo la solución extrajudicial, el fortalecimiento de la JPM y del DDM serían posibles soluciones para la promoción y protección de los Derechos Humanos en Colombia, lo cual contribuiría a la legitimidad del Estado a nivel nacional e internacional, tal como se enunció al inicio de este trabajo. 


\subsection{Solución extrajudicial para que las fuerzas militares promuevan y protejan los Derechos Humanos}

En primer lugar, la incorporación de los miembros de las FF. MM. es una posible solución para la protección de los Derechos Humanos. Se ha observado que es más rigurosa la selección en la Fuerza Aérea y en la Armada Nacional que en el Ejército Nacional, debido al tamańo de esta fuerza respecto de las otras dos.

Al ser coercitivo, el servicio militar obligatorio, de conformidad con la Ley 48 de 1993 (Congreso de la República, 2015), genera que muchas personas que resuelven su situación militar no sean la más idóneas, ni que presten dicho servicio con el debido patriotismo. Muchas de estas personas tienen dependencia de algún tipo de sustancia alucinógena, como lo muestra Peńa (2015) en su estudio sobre soldados bachilleres en el Batallón de Policía Militar N. ${ }^{\circ} 13$.

Algo similar sucede con el personal de oficiales y suboficiales que al incorporarse a las FF. MM. ven en estas una opción de empleo y no una vocación de servicio a la nación, por lo cual hay la necesidad de mejorar la selección para ingresar a dichas fuerzas.

En segundo lugar, enfatizar la importancia de la capacitación en materia de Derechos Humanos, respecto de lo cual, la OCACNUDH, en sus informes anuales, comentados anteriormente, recomienda al Estado fomentar una cultura de los DD. HH. a través de la capacitación. Siendo desarrollada la Política Integral de DD. HH. y DIH del Ministerio de Defensa Nacional y esta a su vez cumplida en cada una de las Fuerzas en las cincos líneas de acción : 1) el Plan Estratégico del Sistema Educativo (PESE), 2) el Modelo Único Pedagógico (MUP), 3) el Grupo por Escenarios Regionales (GEPER), 4) las Lecciones Aprendidas y 5) los Talleres de Capacitación Coyuntural. Así, mediante el PESE y los oficiales de Derechos Humanos se imparte capacitación continua a todos los niveles de las FF. MM. (Ministerio de Defensa Nacional, 2008).

De igual manera, se compilaron en la Cartilla de Directivas de Derechos Humanos y $D I H$, del MDN, las diferentes directrices para la promoción y protección de los DD. HH., las cuales son difundidas para todos los miembros de las FF. MM. y de la Policía Nacional (ver tabla 1). 
Tabla 1. Directivas vigentes de DD. HH. del Ministerio de Defensa Nacional

\begin{tabular}{|c|c|c|}
\hline N. ${ }^{\circ}$ & N. ${ }^{\circ}$ de Directiva & Tema \\
\hline 1 & 09-2003 & Sindicalistas y Defensores de DD. HH. \\
\hline 2 & $09-2005$ & Desplazamiento forzado. \\
\hline 3 & $06-2006$ & Desaparición forzada. \\
\hline 4 & $16-2006$ & Comunidades indígenas. \\
\hline 5 & $01-2007$ & Retorno desplazados (actualizada por la Directiva N. ${ }^{\circ} 17-2015$ ). \\
\hline 6 & $07-2007$ & Comunidades afrocolombianas. \\
\hline 7 & $10-2007$ & $\begin{array}{l}\text { Homicidio en persona protegida (complementada con la Directiva } \\
\text { N. }{ }^{\circ} 19 \text { de } 2007 .\end{array}$ \\
\hline 8 & $25-2008$ & Sistema de quejas. \\
\hline 9 & $10-2009$ & Grupo de doctrina y asesoría jurídica. \\
\hline 10 & $11-2010$ & Cero Tolerancia de la violencia sexual. \\
\hline 11 & $13-2010$ & Diálogo Comité Internacional Cruz Roja. \\
\hline 12 & $07-2011$ & $\begin{array}{l}\text { Medidas de lucha contra la impunidad en casos de graves violaciones } \\
\text { a los DD. HH. e infracciones al DIH. }\end{array}$ \\
\hline 13 & $11-2011$ & Manejo de los archivos operacionales. \\
\hline 14 & $26-2012$ & Protocolo misión periodística. \\
\hline 15 & $36-2012$ & Formación en DD. HH. y DIH. \\
\hline 16 & $16-2014$ & $\begin{array}{l}\text { Sistema integrado de miembros de la fuerza pública víctimas del } \\
\text { conflicto armado. }\end{array}$ \\
\hline 17 & $26-2014$ & $\begin{array}{l}\text { Directrices para la evaluación de las condiciones de seguridad por } \\
\text { parte de la fuerza pública en los procesos de retorno y reubicación } \\
\text { de la población víctima del desplazamiento forzado por la violencia } \\
\text { (modificada por la Directiva N. }{ }^{\circ} 17-2015 \text {. }\end{array}$ \\
\hline 18 & $12-2015$ & Cumplimiento del CONPES 161 de 2013 en equidad de género. \\
\hline 19 & $16-2015$ & $\begin{array}{l}\text { Lineamientos para fortalecer la protección de los } \mathrm{DD} \text {. HH. de la } \\
\text { población rural y semirrural colombiana y el relacionamiento de la } \\
\text { fuerza pública. }\end{array}$ \\
\hline
\end{tabular}

Fuente: Cartilla de Directivas de DD. HH. y DIH del MDN (Ministerio de Defensa Nacional, 2015).

De acuerdo con la información obtenida por las diferentes fuerzas (Ejército Nacional, Armada Nacional y Fuerza Aérea Colombiana), los siguientes son los totales de capacitación en materia curricular y extracurricular en Derechos Humanos. 
Tabla 2. Personal capacitado, curricular y extracurricular, periodo 2004-2014

\begin{tabular}{cccc} 
Ańo & Ejército Nacional $^{*}$ & Armada Nacional $^{* *}$ & Fuerza Aérea*** $^{* *}$ \\
2004 & 12.218 & No informa & No informa \\
2005 & 16.828 & 16.851 & 4.782 \\
\hline 2006 & 31.438 & 12.192 & 5.745 \\
2007 & 58.959 & 8.996 & 5.246 \\
\hline 2008 & 54.347 & 21.081 & 6.084 \\
2009 & 90.367 & 19.815 & 6.858 \\
\hline 2010 & 129.632 & 17.343 & 6.657 \\
2011 & 200.320 & 9.968 & 7.623 \\
\hline 2012 & 102.412 & 15.452 & 8.230 \\
\hline 2013 & 204.097 & 12.755 & 16.962 \\
\hline 2014 & 207.372 & 13.039 & 12.763 \\
\hline
\end{tabular}

*Mediante oficio N. ${ }^{\circ}$ 20158042445303: MDN-CGFM-COEJC-CEJEM-JENIN-DIDEF-1.9 informa estadísticas de Derechos Humanos (Ejército Nacional, 2015).

** Mediante oficio N. ${ }^{\circ}$ 20150041630000649/MDN-CGFM-CARMA-IGAR-DDEHU-29 informa estadísticas de capacitación en Derechos Humanos (Armada Nacional, 2015).

*** Mediante oficio N. ${ }^{\circ}$ 20156400217301/MDN-CGFM-FAC-COFAC-JEMFA-JURDHDIODH-25-11 informando de las capacitaciones en Derechos Humanos (FAC, 2015).

Tal y como se analizó anteriormente, en sus informes de 2004 a 2014, la OCACNUDH recomendó capacitación a las fuerzas militares en DD. HH. y DIH, la cual implementó el Estado colombiano mediante políticas y diferentes directivas que coadyuvaron notablemente a disminuir los casos de violación de Derechos Humanos por parte de dichas FF. MM. (CDHNU, 2015).

En tercer lugar, para la protección de los Derechos Humanos se encuentra la profesionalización de las fuerzas militares, generada por el mismo conflicto y por la necesidad de que quienes detenten las armas lo realicen de la mejor manera (Pizarro, 1987). Convertir la profesionalización en requisito para la estabilidad de las FF. MM. evitará violaciones a los $\mathrm{DD}$. HH. e infracciones al DIH y mostrará eficacia operativa (Atehortúa, 2001), armonizando su función constitucional, más aún con los nuevos desafíos que genera el postacuerdo, dichas FF. MM. deben, además de profesionalizarse, modernizarse para afrontar las nuevas amenazas (Agüero, 1995). Es así como nues- 
tras fuerzas militares se están preparando en cómo deben enfrentarse tales amenazas evitando al máximo algún tipo de violación de los DD. HH. e infracciones al DIH, dependiendo de en qué marco se encuentren desarrollando las operaciones militares.

\subsection{Solución mediante el fortalecimiento de la justicia penal militar}

Con la Constitución Política de 1991, la justicia penal ${ }^{10}$ militar (JPM) ha sufrido varios cambios, pasando del Decreto 2550 de 1988, el cual se mantuvo vigente hasta la Ley 522 de 1999 (Villamil \& Quintero, 2001). Luego se modifica mediante el procedimiento especial para ciertos delitos entre los cuales se encuentran los que afectan el bien jurídico de la disciplina militar con la Ley 1058 de $2006^{11}$; posteriormente, por la Ley 1407 de 2010 (Arboleda, 2015), se crea el sistema penal acusatorio (SPA) en la justicia penal militar, para estar en armonía con líneas nacionales e internacionales del proceso penal y, por último, la Ley 1765 de 2015,con la cual se reestructura la JPM y Policial entre otros (Congreso de Colombia, 2015) ${ }^{12}$.

De los delitos contra los Derechos Humanos, la JPM solo conoce aquellos que se encuentren relacionados con el servicio y que sean cometidos por miembros de la fuerza pública. Tal y como lo enuncia el artículo $1 .^{\circ}$ del Código Penal Militar (Arboleda, 2015), la JPM tiene reducido su fuero penal militar solamente a delitos que se relacionen. En este sentido, la Corte Constitucional se ha pronunciado (Sentencia

10 Como comentario conexo a lo indicado es importante recordar que el sistema penal acusatorio, el cual se origina de un proceso angloamericano, se fue desarrollando a través de los siglos como una forma de ejercer la justicia, la regularización y el arbitraje social (Moreno \& Ballesteros, 2016).

11 En esta Ley en su artículo $1 .^{\circ}$ se enuncia cuáles son los delitos aplicables al procedimiento especial. "Delitos que se juzgan. Los delitos de desobediencia, abandono del puesto, abandono del servicio, abandono del servicio de soldados voluntarios o profesionales, deserción del centinela, violación de habitación ajena, ataque al centinela, peculado por demora en entrega de armas, municiones y explosivos, abuso de autoridad especial, lesiones personales cuya incapacidad no supere los treinta (30) días sin secuelas, hurto simple cuya cuantía no exceda de diez (10) salarios mínimos mensuales legales, hurto de uso, dańo en bien ajeno, abuso de confianza”. (Arboleda Vallejo, 2015).

$12 \mathrm{Al}$ respecto se considera procedente hacer referencia a lo dispuesto por el profesor Edgar Guarín para quien la función que desde el normativismo jurídico se asignó al juez como aplicador de la ley, ha sido desplazada por enfoques que enfatizan en otros aspectos como el de la actividad discursiva y ponderativa, que se proponen como caminos a través de los cuales los derechos se han de materializar (Guarín, 2016). 
C-358 de 1997) y tal y como se enunció anteriormente, la OCACNUDH considera que la JPM solo debe conocer de delitos relacionados con el servicio.

En la medida que se penalicen las conductas transgresoras de los miembros de la fuerza pública, entendidas estas como fuerzas militares y de policía (artículo 216 de la Constitución Política de Colombia), se genera en el colectivo un mecanismo preventivo de violaciones a los Derechos Humanos, entendido que se realicen al exterior como al interior de la institución, pues recordemos que los Derechos Humanos se encuentran transversalizados en todas las actuaciones del ser humano. La finalidad de la pena en materia militar tiene una función de prevención general y, en especial, protectora y de reinserción social (Arboleda, 2015). En este mismo sentido se encuentra la Política Integral de Derechos Humanos y Derecho Internacional Humanitario (PIDH) del Ministerio de Defensa Nacional, al considerar dentro de la segunda línea de acción la Disciplina en la cual está la reforma de la JPM dentro del marco de los DD. HH. y el DIH para garantizar las obligaciones en estas esferas, así mismo la capacitación a los funcionarios en estas materias (Ministerio de Defensa Nacional, 2008) .

\subsection{Solución mediante el fortalecimiento del derecho disciplinario militar}

Es importante el fortalecimiento del derecho disciplinario militar tal como se describió, pues el fundamento para la existencia de toda fuerza es la disciplina ${ }^{13}$, la cual consiste en mandar y obedecer; dentro del marco de los Derechos Humanos, las órdenes deben ser legales, precisas y pertinentes, de lo contrario el subalterno no está en el deber de cumplirlas (Sentencia, C-431, 2004).

En la PIDH del MDN, en la línea de acción dos, incorpora la reforma al régimen disciplinario militar, el cual se está llevando a cabo, con la finalidad de buscar procedimientos orales, más rápidos, eficaces con la mira de ser efectiva la sanción disciplinaria como mecanismo preventivo de la violación de los Derechos Humanos (Ministerio de Defensa Nacional, 2008). De acuerdo con la información obtenida de las diferentes

13 El artículo 17 de la Ley 836 de 2003 entiende la disciplina como: "La disciplina, condición esencial para la existencia de toda fuerza militar, consiste en mandar y obedecer dentro de las atribuciones del superior y las obligaciones y deberes del subalterno; contrarresta los efectos disolventes de la lucha, crea íntima cohesión y permite al superior exigir y obtener del subalterno que las órdenes sean ejecutadas con exactitud y sin vacilación. Implica la observancia de las normas y órdenes que consagra el deber profesional (Mejía, 2003). 
fuerzas (Ejército Nacional, Armada Nacional y FAC) los siguientes son los totales de investigaciones disciplinarias llevadas por violación a los Derechos Humanos:

Tabla 3. Investigaciones disciplinarias por violación a los Derechos Humanos por parte de las fuerzas militares, 2004-2014

\begin{tabular}{cccc|}
\hline Ańo & Ejército $^{*}$ & Armada Nacional $^{* *}$ & Fuerza Aérea $^{* * *}$ \\
\hline 2004 & 182 & 0 & 0 \\
2005 & 239 & 0 & 0 \\
\hline 2006 & 401 & 2 & 0 \\
2007 & 634 & 0 & 0 \\
\hline 2008 & 286 & 0 & 0 \\
\hline 2009 & 13 & 0 & 0 \\
\hline 2010 & 10 & 1 & 0 \\
\hline 2011 & 7 & & 0 \\
\hline 2012 & 3 & & 0 \\
\hline 2013 & 4 & & 0 \\
\hline 2014 & 3 & & 0 \\
\hline
\end{tabular}

*Mediante oficio N. ${ }^{\circ}$ 20158042445303: MDN-CGFM-COEJC-CEJEM-JENIN-DIDEF-1.9 informe estadísticas de Derechos Humanos (Ejército Nacional, 2015).

** Mediante oficio N. ${ }^{\circ}$ 20150041630000649/MDN-CGFM-CARMA-IGAR-DDEHU-29 informe estadísticas de capacitación en Derechos Humanos (Armada Nacional, 2015).

*** Mediante oficio N. ${ }^{\circ}$ 20156390204031/MDN-CGFM-FAC-COFAC-JEMFA-JURDH-DIDIA II-2954 informe estadísticas en Derechos Humanos, informa que no tienen (Fuerza Aérea, 2015).

Como puede observarse en la tabla 3, la fuerza con mayor número de investigaciones por presunta violación a los Derechos Humanos durante el periodo 2004-2014 es el Ejército Nacional con 1783, seguida de la Armada Nacional con 3 casos y la Fuerza Aérea con ninguno.

Asimismo, es procedente analizar los casos que lleva la Procuraduría General de la Nación por poder preferente de las diferentes fuerzas. 
Tabla 4. Investigaciones disciplinarias de las fuerzas militares 2004-2014, por poder preferente que tiene la Procuraduría General de la Nación

\begin{tabular}{lccc} 
Año & Ejército $^{*}$ & Armada Nacional $^{* *}$ & Fuerza Aérea $^{* * *}$ \\
2004 & 0 & 1 & 0 \\
2005 & 2 & 2 & 0 \\
2006 & 6 & 2 & 0 \\
2007 & 9 & 2 & 0 \\
2008 & 69 & 0 & 0 \\
2009 & 203 & 1 & 0 \\
2010 & 330 & 2 & 0 \\
2011 & 625 & 0 & 0 \\
2012 & 635 & 2 & 0 \\
2013 & 473 & 0 & 0 \\
2014 & 390 & 0 & 0 \\
\hline
\end{tabular}

*Mediante oficio N.² 20158042445303: MDN-CGFM-COEJC-CEJEM-JENIN-DIDEF-1.9 informe estadísticas de Derechos Humanos (Ejército Nacional, 2015).

** Mediante oficio N. ${ }^{\circ}$ 20150041630000649/MDN-CGFM-CARMA-IGAR-DDEHU-29 informe estadísticas de capacitación en Derechos Humanos (Armada Nacional, 2015).

*** Mediante oficio N. ${ }^{\circ}$ 20156390204031/MDN-CGFM-FAC-COFAC-JEMFA-JURDH-DIDIA II-2954 informe estadísticas en Derechos Humanos, informa que no tienen (Fuerza Aérea, 2015).

El total de casos que lleva la Procuraduría General de la Nación por presuntas violaciones a los Derechos Humanos por parte del Ejército es de 2973, seguido con 10 casos de la Armada Nacional. La Fuerza Aérea Colombiana manifestó no tener ningún tipo de investigación; esto obedece a que la FAC no mantiene un contacto continuo con el personal civil dentro de sus operaciones militares, las cuales se realizan en apoyo del Ejército Nacional y la Armada Nacional, quienes se encuentran en la primera línea de combate. Para concluir, la relación entre Derechos Humanos y disciplina constituye un vínculo estrecho y necesario para prevenir las violaciones a tales derechos (Alcaldía Mayor de Bogotá, 2011). 


\section{IMPORTANCIA DEL DERECHO DISCIPLINARIO MILITAR EN LA PREVENCIÓN DE VIOlaCiones a los Derechos Humanos}

Como se ha venido reiterando en el presente trabajo, es muy importante el papel que cumple el DDM para la promoción y protección de los Derechos Humanos, algo que el mismo Estado ha evidenciado con la PIDH del MDN. Tal y como se dijo, se encuentra en la segunda línea de la misma, la cual requiere una reforma radical para contar con un mecanismo eficaz de prevención en el marco disciplinario. A continuación, se analiza la efectividad del DDM, pasando por una crítica al mismo y finalizando con una propuesta para coadyuvar a la mejora del DDM a fin de promover y proteger los Derechos Humanos, generando seguridad nacional e internacional de las actuaciones que se realizan.

\subsection{Efectividad del derecho disciplinario militar}

Según se mencionó, la disciplina es la piedra angular para la existencia de las fuerzas militares, de modo que para hacer exigible ese deber-valor, es necesario contar con el DDM que actúa como mecanismo de prevención y correctivo (Mejía, 2006), realizado por el funcionario militar que tenga la competencia y sin necesidad de ir a otros mecanismos demorados, como es el penal militar que suele dejar malestar y pesadumbre.

De acuerdo con las quinces (15) sentencias contra Colombia, enunciadas anteriormente, la CIDH es reiterativa en manifestar que la justicia penal militar es ineficaz y parcial demostrando una denegación de la justicia (Corte Interamericana de Derechos Humanos, 2014); en muchos casos han archivado las investigaciones penales sin un argumento serio, generando una desconfianza a nivel nacional e internacional, motivo por el cual la CIDH considera que no existen las garantías judiciales para la verdad, la justicia y la reparación, generando impunidad.

Por el contrario, respecto del DDM no ha habido referencia negativa, lo que señala la importancia de fortalecerlo para prevenir las violaciones de los Derechos Humanos tanto al interior de la fuerza en la relaciones de sujeción del personal militar, como al exterior en la relación con la población civil, en aras de consolidar la legitimidad del Estado y mejorar su imagen, al evitar demandas a nivel nacional e internacional. 
Como se explicó en la tabla 3, Investigaciones disciplinarias por violación a los Derechos Humanos por parte de las fuerzas militares, 2004-2014, muchas de las veces las investigaciones disciplinarias se encuentra iniciadas en la oficina de control interno de las fuerzas, las cuales están más adelantadas que las investigaciones penales militares, de donde solicitaban el traslado de las pruebas al expediente disciplinario.

De la información suministrada por las diferentes fuerzas respecto de las investigaciones disciplinarias, se observa que durante el periodo 2004-2014, el Ejército Nacional realizó 1783 investigaciones de las cuales 100 fueron falladas; 442, absueltas; 788, archivadas y solo 453 se encuentran en trámite (Ejército Nacional, 2015). En la Armada Nacional de las tres investigaciones por Derechos Humanos, las tres se encuentran falladas (Armada Nacional, 2015) y, por último, la Fuerza Aérea Colombiana manifiesta no tener ningún tipo de investigación disciplinaria en Derechos Humanos (FAC, 2015).

Puede evidenciarse entonces que el DDM es efectivo, lo cual obedece a que al interior de las fuerzas militares existen varios controles para prevenir la prescripción de las investigaciones, entre ellos, la Inspección General de las Fuerzas Militares que realiza diferentes inspecciones a las fuerzas. En este sentido, se encuentra al interior del Ejército Nacional, la Armada Nacional y la Fuerza Aérea la inspección para la correspondiente verificación de las investigaciones (FF. MM., Comando General, 2015), a lo que se aúnan los inspectores delegados, creados con la PIDH del MDN, en la segunda línea de disciplina (Ministerio de Defensa Nacional, 2008) ${ }^{14}$.

Con el fortalecimiento del DDM se cumple con las diferentes obligaciones por parte del Estado y las recomendaciones de la OCACNUDH de realizar actividades tendien-

14 Es importante aclarar que la PIDH del MDN tiene cinco líneas de acción: 1) Instrucción que comprende el Plan Estratégico del Sistema Educativo (PESE), Modelo único pedagógico (MUP), Grupo de Entrenamiento por Escenarios Regionales (GEPER), Lecciones aprendidas y talleres coyunturales ,2) Disciplina que comprende la Oficina de Doctrina y Asesoría (ODA), Asesores Jurídicos Operacionales, la orden de operaciones y las RDE, Inspectores Delegados, Sistematización (SIJUR), reforma al régimen disciplinario, reforma al régimen de la justicia penal militar y directivas ministeriales de control (Directiva N. $\left.{ }^{\circ} 10\right)$, 3) Defensa que comprende Defensa técnica, defensa del Estado, conciliación extrajudicial, 4) Atención, que comprende atención especial a los grupos especiales, oficiales enlace, relación con el sector empresarial y desminado, y 5) Cooperación con las diferentes entidades gubernamentales y no gubernamentales (CICR, OCACNUDH y países amigos); sus objetivos se encuentran encaminados a cumplir las cinco líneas de acción (Ministerio de Defensa Nacional, 2008). 
tes a la promoción y protección de los DD. HH. y la prevención de sus violaciones por parte de los miembros de las fuerzas militares de Colombia (CDHNU, 2007).

\subsection{Debilidades del derecho disciplinario militar}

Recordemos que los Derechos Humanos están transversalizados en todas las actuaciones del ser humano y se exige el deber de respeto y de garantía por parte del Estado colombiano, por lo que los funcionarios tienen la obligación de promover y proteger tales Derechos Humanos.

Como se analizó anteriormente, desde 1911 a la actualidad, el DDM ha realizado quince reformas, la mayoría con la Constitución de 1886; dichas reformas obedecieron en su momento a la política del Estado y a la necesidad imperiosa de evolucionar. Por tal razón, toda reforma debe realizarse de manera concienzuda y de acuerdo con los retos que se tiene en el DDM, con el fin de evitar otras muchas reformas que al final generan inseguridad jurídica y desestabilización del mismo DDM.

Si bien el derecho disciplinario militar es un mecanismo que coadyuva a la promoción y protección de los DD. HH., en la actualidad tiene falencias que generan demora y desconfianza institucional; por tal motivo y fundamentado en la Política Integral de DD. HH. y DIH del MDN, el señor coronel Dagoberto Gómez Cortés manifiesta en entrevista que:

Esta reforma lleva varios años en el Comando General de las FF. MM. en el nuevo proyecto de ley del DDM, el cual va apoyarse en la dignidad humana, de manera objetiva, transparente e independiente en aras de generar confianza a nivel nacional e internacional. Con este propósito, el proceso será oral, en consonancia con la actualidad de los procedimientos, para así ser más eficaz y evitar la impunidad de las actuaciones del militar. Se despenalizan las faltas disciplinarias, pues en el actual DDM casi todos los delitos son faltas disciplinarias, lo que causa dualidad y congestión del mismo, y en ese sentido, los tipos de faltas que se lleguen a cometer serán conforme al ser y actuar militar (Gómez, 2015). 
El reto consiste en que la reforma al DDM se realice de tal manera que perdure en el tiempo, previniendo múltiples reformas que generan impunidad y violaciones a los Derechos Humanos, ya sea en las víctimas o en el personal militar que se encuentra vinculado en algún tipo de investigación de carácter disciplinario.

\section{Propuesta para fortalecer el Derecho disciplinario militar}

Una vez realizada la investigación y analizadas sus diferentes partes (historia del derecho disciplinario militar, situación actual del DDM en Colombia, posibles soluciones extrajudiciales, penales y disciplinarias, con la finalidad de resolver la pregunta qué función cumple el DDM en la promoción y protección de los Derechos Humanos por parte de las fuerzas militares en Colombia, la propuesta y estrategia para la prevención de violaciones a los DD. HH. es el fortalecimiento del DDM.

Para esto es importante que una eventual reforma se encuentre dentro de los parámetros y estándares nacionales e internacionales, en especial en materia de Derechos Humanos, tal y como lo menciona el Cr. Gómez en su entrevista. De igual manera, el personal militar encargado de orientar la investigación y juicio debe estar debidamente capacitado para llevar a feliz término el proceso y para que exista al interior de la fuerza el respeto de la especialidad del Oficial Asesor Jurídico en materia disciplinaria, como existe en materia de Derechos Humanos y Operacional.

Aunado a lo anterior, debe continuarse con la capacitación al interior de las FF. MM., de manera multidisciplinaria en todos los temas que el militar debe conocer y manejar en aras de cumplir a cabalidad su función y de esta manera, evitar sanciones por violaciones a los Derechos Humanos, de acuerdo con el análisis realizado a los diez informes de la OCACNUDH y a las estadísticas de capacitación relacionadas en la tabla 2, donde se demuestra que a mayor capacitación, mayor disminución de las violaciones a los DD. HH., en especial las muertes cuestionadas en combate.

Por lo anterior, se considera que es importante el fortalecimiento del DDM de manera multidisciplinaria, pues las FF. MM. van a enfrentarse a los retos que conlleva un postacuerdo y a la transformación de las nuevas amenazas, según los roles que deban desempeñar tales fuerzas para cumplir con la función constitucional, sin co- 
meter violaciones a los DD. HH. que no son solamente con la vida, sino contra todo aquello que sea necesario para la dignidad y la supervivencia del ser humano, entendido como un todo y en relación con el medio ambiente en que se desenvuelve.

Para concluir, debe fortalecerse el DDM de manera interdisciplinaria y continuando con la capacitación y profesionalización del personal militar que realiza esta labor, con la finalidad de no solo promover y proteger los Derechos Humanos, sino de evitar demandas a nivel nacional e internacional por el actuar omisivo, activo o de extralimitación de nuestros hombres tal como lo consagra la Constitución Política en el artículo 6. ${ }^{015}$ (Const., 1991).

\section{Conclusiones}

Colombia ha ratificado los convenios y tratados en materia de Derechos Humanos, motivo por el cual debe cumplir las obligaciones a nivel nacional e internacional; su incumplimiento ha generado como resultados quince sentencias de la Corte Interamericana de Derechos Humanos, en las cuales la CIDH ha manifestado que la justicia penal militar es ineficiente en las investigaciones y que muchos de los casos que se tramitan terminan en impunidad.

La OCACNUDH ha realizado entre 1997 y 2014, 17 informes en los cuales describe y analiza la situación en materia de Derechos Humanos y genera recomendaciones para el Estado. Para los fines del presente trabajo, se estudiaron los informes del periodo 2004-2014, con el propósito de realizar un estudio sobre el cumplimiento de la Ley 836 de 2003 o régimen disciplinario para las FF. MM. de Colombia, observándose que debido al conflicto armado y al escalonamiento del mismo, se generó una serie de violaciones a los Derechos Humanos por parte de los actores del mismo, por lo que se creó la PIDH y las diferentes directivas enunciadas en la tabla 1.

15 Se transcribe el artículo $6 .^{\circ}$ de la Constitución Política: "Los particulares solo son responsables ante las autoridades por infringir la Constitución y las leyes. Los servidores públicos lo son por la misma causa y/o omisión o extralimitación en el ejercicio de sus funciones". 
La capacitación del personal militar es importante para la promoción y respeto de los Derechos Humanos como lo demuestran las estadísticas de las FF. MM. En ellas puede verse cómo a medida que se aumentaba la capacitación, se disminuían notablemente las violaciones de Derechos Humanos, esto en relación con los diez informes analizados de la OCACNUDH.

La disciplina, como fundamento para la existencia de las FF. MM., requiere de una reforma del DDM, en aras de adecuar el procedimiento que se tiene de la oralidad y despenalizar las faltas disciplinarias que generan congestión y confusión al interior de la fuerza. En este sentido, se armoniza con el DDM de países como Canadá y Estados Unidos, haciendo más efectivas y eficaces las sanciones y generando la promoción y protección de los Derechos Humanos.

El DDM cumple un papel fundamental para la protección de los DD. HH., conforme a los retos que deberán enfrentar las FF. MM. en el postacuerdo, pues estas deben transformarse conforme a las nuevas amenazas que van a enfrentarse.

El DDM no puede ser aislado de la demás disciplinas; debe armonizarse de tal manera que se pueda cumplir el fin para el cual fue creado que es mantener la disciplina y así poder coadyuvar a la promoción y protección de los Derechos Humanos.

\section{REFERENCIAS}

Agüero Piwonka, F. (1995). Militares, civiles y democracia. Madrid: Alianza Editorial.

Alcaldía Mayor de Bogotá (2011). Derechos Humanos y derecho disciplinario. Bogotá: Alcaldía Mayor de Bogotá.

Alto Comisionado de las Naciones Unidas para los DD. HH. (2003). Compilación de las normas nacionales de los Derechos Humanos. Bogotá: Naciones Unidas.

Arboleda Vallejo, M. (2015). Código penal militar sustantivo y procesal. Bogotá: Leyer.

Atehortúa Cruz, A. L. (2001). Las fuerzas militares en Colombia: de sus origenes al Frente Nacional. Recuperado el 15 de septiembre de 2015, de http://bibliotecadigital.univalle.edu. 
co/bitstream/10893/7401/1/Las\%20fuerzas\%20militares\%20en\%20Colombia $\% 20$ -\%20Atehortua\%20Adolfo.pdf

Colombia, Armada Nacional (2015). Respuesta a información temas de Derechos Humanos, 29 de septiembre. Bogotá: Inspección General de la Armada Nacional.

Colombia, Congreso de la República. Ley 48 de 1993, por la cual se reglamenta el servicio de reclutamiento y movilización.

Colombia, Congreso de la República. Ley 836 de 2003, por la cual se expide el reglamento del régimen disciplinario para las fuerzas militares.

Colombia, Congreso de la República. Ley 975 de 2005, por la cual se dictan disposiciones para la reincorporación de miembros de grupos armados organizados al margen de la ley.

Colombia, Congreso de la República. Ley 1765 del 23 de julio de 2015, por la cual se reestructura la justicia penal militar, entre otros.

Colombia, Corte Constitucional. Demanda de inconstitucionalidad contra algunos artículos del Código Penal Militar, Decreto 2550 de 1988, C-358 de 1997, 5 de agosto de 1997.

Colombia, Corte Constitucional. Sentencia, C-578, 30 de julio de 2002.

Colombia, Corte Constitucional. Sentencia, C-431, 6 de mayo de 2004, M. P. Marco Gerardo Monroy Cabra.

Colombia, Corte Constitucional. Sentencia, C-500, 16 de julio de 2014. M. P. Mauricio González Cuervo.

Colombia, Corte Constitucional. Sentencia C-728 de 2009. M.P. Gabriel Eduardo Mendoza Martelo.

Colombia, Corte Constitucional. Sentencia T-363 de 1995. M.P. José Gregorio Hernández Galindo.

Colombia, Ejército Nacional (2015). Respuesta tema de Derechos Humanos del Ejército Nacional desde el año 2004 hasta el mes de junio de 2015. Bogotá: Dirección de Defensa Jurídica Integral del Ejército Nacional.

Colombia, Fuerza Aérea (2015). Respuesta temas de Derechos Humanos, 19 de septiembre. Bogotá: Jefatura Jurídica y Derechos Humanos de la FAC. 
Colombia, Fuerza Aérea (2015). Informe tema de Derechos Humanos, 13 de octubre. Bogotá: Jefatura Jurídica y Derechos Humanos de la FAC.

Colombia, Fuerzas Militares (1980). Decreto 1776 de 1979. Bogotá: Imprenta y publicaciones de las fuerzas militares.

Colombia, Fuerzas Militares, Comando General (2015). Inspección General de las Fuerzas Militares, 3 de octubre. Recuperado de: cgfm.mil.co: http://cgfm.mil.co/

Colombia, Ministerio de Defensa Nacional (2000). Las fuerzas militares del siglo XXI, nueva Legislación. Bogotá: Ministerio de Defensa Nacional.

Colombia, Ministerio de Defensa Nacional (2008). Politica integral de DD. HH. y DIH. Bogotá: Ministerio de Defensa Nacional.

Colombia, Ministerio de Defensa Nacional (2014). Cartilla de Directivas de Derechos Humanos y DIH. Bogotá: Imprenta Nacional de Colombia.

Colombia, Ministerio de Defensa Nacional (2015). Cartilla de Directivas de Derechos Humanos y DIH. Bogotá: Imprenta Nacional de Colombia.

Colombia, Policía Nacional (2015). Avances acuerdo de La Habana, 1. ${ }^{\circ}$ de octubre. Recuperado de: http://oasportal.policia.gov.co/portal/page/portal/HOME/avancesacuerdos

Colombia, Procuraduría General de la Nación (2002). Resolución N. ${ }^{\circ} 346$. Bogotá: Procuraduría General de la Nación.

Consejo de Derechos Humanos Naciones Unidas (1998). Informe de la Alta Comisionada de las Naciones Unidas para los Derechos Humanos. Ginebra: Naciones Unidas.

Consejo de Derechos Humanos Naciones Unidas (2005). Informe de la Alta Comisionada de las Naciones Unidas para los Derechos Humanos sobre la situación de los Derechos Humanos en Colombia, año 2004. Bogotá: Naciones Unidas.

Consejo de Derechos Humanos Naciones Unidas. (2006). Informe de la Alta Comisionada de las Naciones Unidas para los Derechos Humanos sobre la situación de los Derechos Humanos en Colombia, año 2005. Bogotá: Naciones Unidas. 
Consejo de Derechos Humanos Naciones Unidas. (2007). Informe de la Alta Comisionada de las Naciones Unidas para los Derechos Humanos sobre la situación de los Derechos Humanos en Colombia, año 2006. Bogotá: Naciones Unidas.

Consejo de Derechos Humanos Naciones Unidas (2008). Informe anual del Alto Comisionado de las Naciones Unidas para los Derechos Humanos e informes de la oficina del Alto Comisionado y del Secretario General para Colombia, año 2007. Bogotá: Naciones Unidas.

Consejo de Derechos Humanos Naciones Unidas (2009). Informe de la Alta Comisionada de las Naciones Unidas para los Derechos Humanos sobre la situación de los Derechos Humanos en Colombia, año 2008. Bogotá: Naciones Unidas.

Consejo de Derechos Humanos Naciones Unidas. (2010). Informe de la Alta Comisionada de las Naciones Unidas para los Derechos Humanos sobre la situación de los Derechos Humanos en Colombia, año 2009. Bogotá: Naciones Unidas.

Consejo de Derechos Humanos Naciones Unidas. (2011). Informe de la Alta Comisionada de las Naciones Unidas para los Derechos Humanos sobre la situación de los Derechos Humanos en Colombia, año 2010. Bogotá: Naciones Unidas.

Consejo de Derechos Humanos Naciones Unidas. (2012). Informe de la Alta Comisionada de las Naciones Unidas para los Derechos Humanos sobre la situación de los Derechos Humanos en Colombia, año 2011. Bogotá: Naciones Unidas.

Consejo de Derechos Humanos Naciones Unidas. (2013). Informe de la Alta Comisionada de las Naciones Unidas para los Derechos Humanos sobre la situación de los Derechos Humanos en Colombia, año 2012. Bogotá: Naciones Unidas.

Consejo de Derechos Humanos Naciones Unidas. (2014). Informe de la Alta Comisionada de las Naciones Unidas para los Derechos Humanos sobre la situación de los Derechos Humanos en Colombia, año 2013. Bogotá: Naciones Unidas.

Consejo de Derechos Humanos Naciones Unidas. (2015). Informe de la Alta Comisionada de las Naciones Unidas para los Derechos Humanos sobre la situación de los Derechos Humanos en Colombia, año 2014. Bogotá: Naciones Unidas.

Constitución política de Colombia (1991). Bogotá: Leyer.

Corte Interamericana de Derechos Humanos (2014). Caso Rodriguez Vera y otros (Desaparecidos del Palacio de Justicia), Sentencia de 14 de noviembre de 2014. 
Corte Interamericana de Derechos Humanos (2015). Casos Contenciosos CIDH, 7 de septiembre. Recuperado de: http://www.corteidh.or.cr/cf/Jurisprudencia2/busqueda_casos_contenciosos.cfm?lang=es

Echandía Castilla, C. (2006). Dos décadas de escalamiento del conflicto armado en Colombia 1986-2006. Bogotá: Universidad Externado de Colombia.

Gómez Cortés, D. (2015). Reforma al régimen disciplinario de las fuerzas miliares. (D. Y. Montero Perdomo, entrevistador), 13 de agosto.

Guarín, Edgar (2016). La libertad de los jueces para fallar en positivo. Bogotá: Editorial Ibánez. Recuperado de: http://porticus.usantotomas.edu.co/bitstream/11634/1482/1/La\%20libertad\%20de\%20los\%20Jueces.pdf

Instituto Colombiano de Derecho Disciplinario (2012). Estado actual del derecho disciplinario en Colombia. Colección jurídica disciplinaria, ICDD, 512.

Madrid-Malo, M. (1995). Estudio sobre el derecho a la objeción de conciencia. Defensoría del Pueblo.

Maquiavelo, N. (2005). El arte de la guerra. Ediciones Leyenda. México.

Mejía Ossman, J. (2003). Reglamento del régimen disciplinario para las fuerzas militares de Colombia. Bogotá: Panamericana Formas e Impresos S. A.

Mejía Ossman, J. (2006). Principios constitucionales y legales, ley disciplinaria fuerzas militares. Bogotá: Ediciones Doctrina y Ley Ltda.

Moreno Álvaro \& Ballesteros Constanza (2016). "Sistema penal acusatorio y el habitus jurídico”, en Oralidad y Derecho, pp. 17-49. Bogotá: Editorial Ibánez. Recuperado de: http:// porticus.usantotomas.edu.co/bitstream/11634/1450/1/Oralidad\%20y\%20derecho.pdf

Peña Ramírez, H. (2015). Cómo evitar la incorporación de ciudadanos consumidores de drogas alucinógenas como soldados bachilleres del Batallón de Policía Militar N. ${ }^{\circ} 13$. Recuperado de: http://repository.unimilitar.edu.co/bitstream/10654/12526/1/TRABAJO\%20 DE\%20INVESTIGACION\%20ESPAG\%20HENRY\%20PE\%C3\%91A.pdf

Pizarro Leongómez, E. (1987). "La profesionalización militar en Colombia II: el periodo de la violencia”. En Análisis Político (2), 174, septiembre-diciembre.

Rojas Caro, J. (1990). Derecho Disciplinario Militar. Madrid: Tecnos. 
Valencia Villa, H. (2012). Cartas de batalla. Bogotá: Panamericana.

Villamil Jaramillo, E. A., \& Quintero Torres, M. C. (2001). Principios rectores y estructura del proceso penal en el sistema acusatorio en el nuevo Código Penal militar. Recuperado de: http://javeriana.edu.co/biblos/tesis/derecho/dere2/Tesis49.pdf 